\title{
Trimetazidine Protects Umbilical Cord Mesenchymal Stem Cells Against Hypoxia and Serum Deprivation Induced Apoptosis by Activation of Akt
}

\author{
Xuhe Gong ${ }^{\mathrm{a}}$ Guangpu Fan ${ }^{\mathrm{b}}$ Wei Wang ${ }^{\mathrm{b}}$ Guogan Wang \\ aEmergency and Critical Center, Department of Cardiovascular Disease, State Key Laboratory of \\ Cardiovascular Disease, Fuwai Hospital, National Center for Cardiovascular Diseases, Chinese Academy \\ of Medical Sciences and Peking Union Medical College, ${ }^{b}$ Cardiovascular Surgery Department, State \\ Key Laboratory of Cardiovascular Disease, Fuwai Hospital, National Center for Cardiovascular Diseases, \\ Chinese Academy of Medical Sciences and Peking Union Medical College, Beijing, People's Republic of \\ China
}

\section{Key Words}

Trimetazidine $\cdot$ Umbilical cord MSCs • Apoptosis • Hypoxia and serum deprivation • Signaling pathway

\begin{abstract}
Background: Mesenchymal stem cell (MSC) transplantation is a promising therapy for cardiac repair. However, the efficacy is limited by the poor viability of MSCs in the infarcted heart. Recent findings have implicated that trimetazidine (TMZ) enhanced the survival of the stem cells under various conditions. However, as the stem cells in these studies were animalderived, little information is available about the effects of TMZ on human MSCs. Herein, we propose that TMZ may protect human MSCs against apoptosis induced by Hypoxia/Serum deprivation (H/SD). Methods: Human umbilical cord MSCs (UC-MSCs) from Wharton's jelly were pretreated with $10 \mu \mathrm{M} \mathrm{TMZ}$ of H/SD with or without the Akt inhibitor LY294002. The morphological changes were assessed using Hoechst 33342. Apoptosis was evaluated via Annexin V/PI staining; and apoptosis-related proteins were detected using Western-blot. Protein chip technology was used to screen for differences between the cell supernatants. Results: TMZ had a significant protective effect against H/SD-induced apoptosis, accompanied by an increase in Bcl-2 and p-Akt. The TMZ-mediated anti-apoptotic effect on MSCs could be attenuated by treatment with LY294002. Moreover, protein chip assays showed that TMZ treatment increased the paracrine functions of MSCs. Conclusion: Trimetazidine protects human UC-MSCs from H/SD-induced apoptosis via the Akt pathway and may therefore be a potentially useful therapeutic adjunct for transplanting MSCs into damaged heart after myocardial infarction.
\end{abstract}




\section{Introduction}

Despite the progress of medicine and therapeutic strategies, ischemic cardiovascular disease, which is associated with progressive heart failure, arrhythmias and sudden death, remains the most life-threatening health problem worldwide [1, 2]. The potential severity to patients emphasizes the importance of novel and effective therapeutic strategies for ischemia cardiomyopathy.

Currently, cell-based therapies are a promising strategy for heart diseases; evidence from both animal studies and clinical investigations have demonstrated that mesenchymal stem cells (MSCs) can ameliorate heart injuries during ischemia cardiomyopathy [3-5]. However, in many experiments the transplanted cells showed poor viability and increased apoptosis due to the lack of blood and oxygen to the infarcted myocardium $[6,7]$. Therefore, this study aimed to enhance the survival of MSCs in ischemia and hypoxia environment.

Trimetazidine (TMZ), a well-established anti-ischemic drug, has been used successfully for the treatment of ischemic cardiomyopathy [8]. Recent findings have implicated that it can enhance the survival of stem cells under various conditions, such as reducing the $\mathrm{H}_{2} \mathrm{O}_{2}$ induced injury of endothelial progenitor cells [9] and the hypoxia-induced apoptosis of bone marrow MSCs [10]. However, as stem cells used in these studies were mainly animalderived, little information is available on whether TMZ protects human MSCs from apoptosis induced by hypoxia and serum deprivation (H/SD). Human umbilical cord MSCs (UC-MSCs) offers several advantages over other MSCs: they are easy to expand, non-invasive, can be produced in large quantities, and have a lower frequency of viral contamination, which are an alternative source of MSCs for regenerative therapies [11,12]. To address this issue, we focused on UC-MSCs. In the present study, we postulated that TMZ would protect UC-MSCs against apoptosis under H/SD conditions.

\section{Materials and Methods}

\section{MSCs isolation and culture}

Protocols for obtaining human umbilical cords were approved by the Fuxing Hospital, Capital Medical University; the current study complies with the Helsinki Declaration. Isolation of human UC-MSCs was performed as described [11]. Cells were cultured in Dulbecco's modified Eagle's medium/F12 (DMEM/F12, Hyclone) supplemented with $10 \%$ fetal bovine serum (FBS, Gibco) and $1 \%$ penicillin/streptomycin. The media was first replaced after a 5 days incubation to promote tissue adherence. Thereafter, the media were replaced every 2-3 days until putative MSC colonies were visible under a microscope. The MSC colonies were expanded and passaged 3 times being used in the experiment.

\section{Identification of MSCS}

MSCs were characterized by cell morphology, surface antigens and differentiation, the minimum criteria defining MSCs [13]. The cells were trypsinized and incubated with fluorochrome-conjugated antibody for 10 minutes in the dark at $4^{\circ} \mathrm{C}$; CD34-FITC, CD44-PE, CD45-PercP and CD105-APC (Miltenyi Biotec, Germany) expression was identified using flow cytometry. Human MSC osteogenesis and adipogenesis medium (Cyagen, China) were used for differentiation assays. After 2-3 weeks, osteogenic differentiation was evaluated via Alizarin Red S staining and adipogenic potential was assessed via Oil Red 0 staining.

Induction of hypoxia and drug application

TMZ was purchased from sigma, dissolved in DMEM/F12 medium (serum-free) and diluted to a final concentration of $10 \mu \mathrm{M}$. The optimal dose of TMZ was determined using a preliminary dose study [14]. For the TMZ protection experiments, MSCs were washed twice with phosphate-buffered saline (PBS), and then

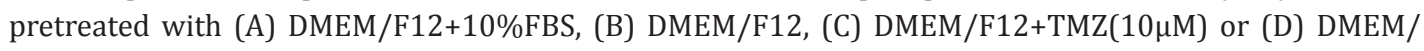
F12+TMZ+Akt inhibitor LY294002 $(25 \mu \mathrm{M})$.

It is well known from the literature that hypoxia is protective for stem cells. In previous studies, the hypoxia was not a completely anaerobic state but rather had low oxygen levels (such as $1 \%, 2 \%$ ), and the 


\section{Cellular Physiology $\quad$ Cell Physiol Biochem 2014;34:2245-2255 and Biochemistry \begin{tabular}{l|l} 
DOI: 10.1159/000369667 \\
Published online: December 08, 2014 & $\begin{array}{l}\text { O 2014 S. Karger AG, Basel } \\
\text { www.karger.com/cpb }\end{array}$ \\
\cline { 2 - 3 }
\end{tabular} \\ Gong et al.: Trimetazidine Reduces Apoptosis of Mesenchymal Stem Cells by Activation of Akt}

hypoxia conditions were generated using a hypoxia incubation box, such as a BioSpherix (Redfield, NY) growth chamber. However, in the present experiment, we used oxygen chelation methods, the cells in the $\mathrm{B}, \mathrm{C}$ and D group were put in a sealed, hypoxic GENbox jar fitted with a catalyst (Bio-Me'rieux) to scavenge free oxygen, which resulted in continuously decreasing oxygen levels until anoxia. The oxygen tension in the medium was measured using an anaerobic indicator. Group A was in normal environment as a control.

\section{Morphological profiles of H/SD induced MSCS}

Morphological profiles were assessed via staining with the chromatin dye Hoechst 33342 (Beyotime, China). The cells were incubated in the H/SD environment for $12 \mathrm{~h}$, washed twice with PBS, fixed with $4 \%$ paraformaldehyde for $10 \mathrm{~min}$, and washed with PBS again. The cells were then incubated with the Hoechst 33342 fluorochrome $(5 \mathrm{mg} / \mathrm{L}$ ) for $30 \mathrm{~min}$ at room temperature (protected from light) and rewashed with PBS twice. Observations were immediately conducted under a fluorescent microscope (Leica, Germany), and the cells were characterized by morphological alteration such as condensed nuclei and cell shrinkage.

\section{Measurement of cellular proliferation}

MSCs were seeded in a 96-well plate (3000 cells/well) and cultured for 12 hours to allow attachment. Then cells were treated with different intervention in H/SD environment, after $12 \mathrm{~h}$ of cultivation, the proliferation rates were measured via MTT. Briefly, 20ul of MTT solution $(5 \mathrm{mg} / \mathrm{ml})$ was added into each well for $4 \mathrm{~h}$ at $37^{\circ} \mathrm{C}$ in dark. The supernatant was then discarded; $150 \mu \mathrm{l}$ of dimethyl sulfoxide was added to each well and mixed well. The optical density (OD) value per well was measured using an enzyme-labeling instrument at $490 \mathrm{~nm}$.

\section{Apoptosis analysis}

Apoptotic cell death was measured via flow cytometry using FITC-conjugated Annexin V/PI assay. Briefly, the cells were harvested using $0.25 \%$ trypsinization and washed twice with PBS. Then, $10^{6} \mathrm{MSCs}$ were resuspended in $300 \mu$ l of binding buffer and incubated with $5 \mu$ of FITC-conjugated Annexin V and $5 \mu \mathrm{l}$ of PI for $10 \mathrm{~min}$ at room temperature in the dark. Finally, flow cytometry analyses of 10,000 cells were performed to measure apoptosis.

\section{Cell survival assessment}

After exposure to hypoxia for $12 \mathrm{~h}$, the MSCs in the different groups were harvested by trypsinization and resuspended in $50 \mu \mathrm{l}$ PBS per $5^{*} 10^{5}$ cells. Then, $450 \mu$ l Muse Count and Viability reagent was added (Millipore, Darmstadt, Germany), and the cells were incubated for $5 \mathrm{~min}$ at room temperature in the dark. Finally, the cell suspensions were analyzed using the Muse Cell Analyzer.

\section{Protein chip assay}

In this study, we used the Biotin label-based Human Antibody Array I (RayBio) to compare the differences in the protein expression levels between the H/SD group and the H/SD+TMZ group. This antibody array membrane is marked with 507 specific antibodies toward cytokines, chemokines, growth factors, angiogenic factors and other proteins, allowing it to comprehensively analyze differences in protein expression. Cultured MSCs were exposed to H/SD with or without TMZ, and after $12 \mathrm{~h}$, the culture medium was harvested and centrifuged for the protein chip assay; the assay was performed according to the manufacturer's instructions.

\section{Western blot analysis}

Western blot analyses for Bcl-2, caspase-3 and phosphorylate Akt (p-Akt) were performed for each group. Proteins were separated by $12 \%$ SDS-PAGE and transferred onto a polyvinyli-dene difluoride membrane. After blocking with $0.1 \%$ Tween in Tris-buffered saline containing $5 \%$ skim milk at room temperature for 2 hours, the membranes were incubated with primary antibodies against p-Akt, Bcl-2 and caspase-3 $(1: 1000$, CST $)$ overnight at $4^{\circ} \mathrm{C}$. The next day, after washing, the membranes were incubated for 2 hours at room temperature with peroxidase-conjugated secondary antibodies. Finally, the protein bands were detected using a chemiluminescence detection system (FluorChem M, USA); $\beta$-actin was used as a standard reference. 


\section{Cellular Physiology and Biochemistry
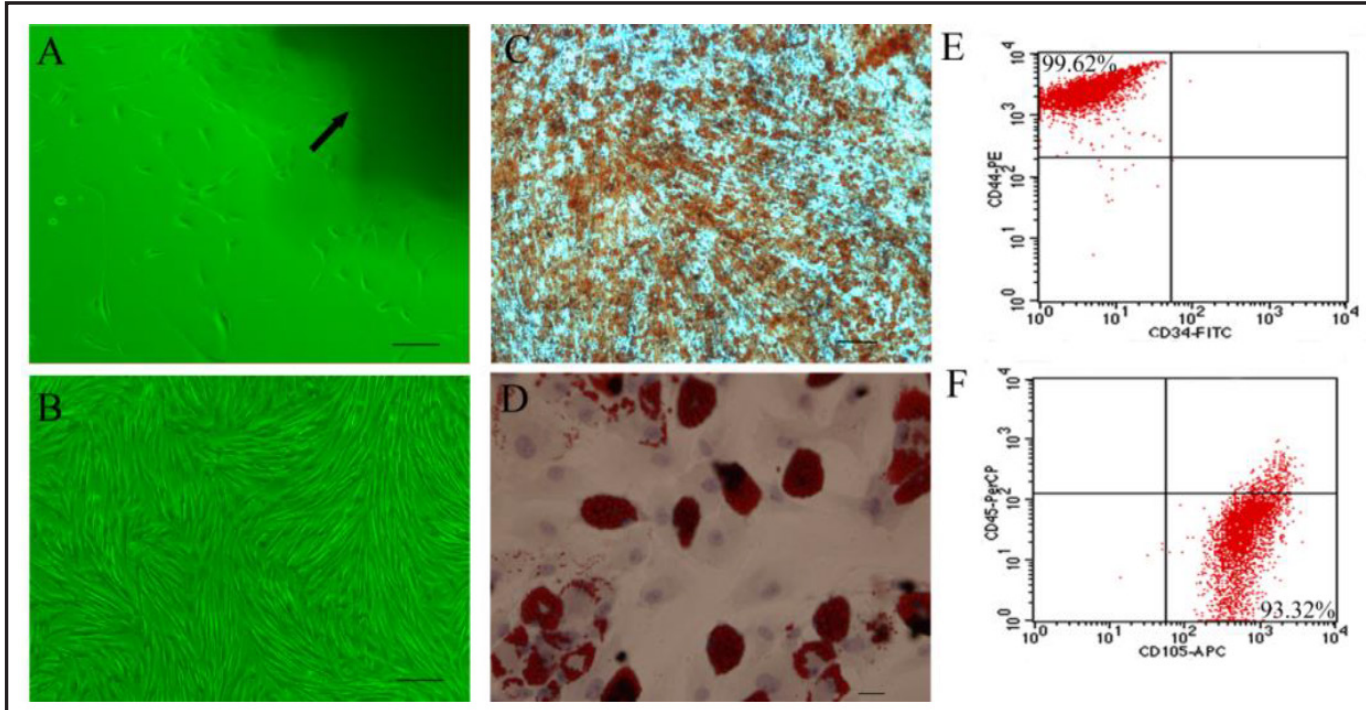

Fig. 1. Characterization of human mesenchymal stem cells (MSCs) from UC. (A, B) Morphology of cultured MSCs at various time points. All MSCs exhibited spindle-shaped morphology after five days (A) and two weeks (B). The arrow in figure A represents the umbilical cord tissue. Adherent cells were transformed quickly from tissue pieces and displayed a fibroblastic morphology. (C) Osteogenic differentiation demonstrated by the deposition of a mineralized matrix, as detected by alizarin red staining, 100X, scale bar $=100 \mathrm{um}$. (D) Adipogenic differentiation demonstrated by the accumulation of lipid vacuoles, as indicated by Oil Red 0 staining, 200X, scale bar=50um. (E, F) Surface marker expression of MSCs, MSCs at passage 3 were positive for mesenchymal markers CD105 and CD44, but negative for haematopoietic markers CD34 and CD45, as indicted by flow cytometry analysis.

\section{Statistical analysis}

Statistical analysis was performed with the SPSS 20.0 software (SPSS Inc., USA). Data were expressed as the mean \pm standard deviation (SD) from at least 3 independent experiments. Univariate comparisons of the means were evaluated using Student's t-test, and multiple comparisons were evaluated using one-way analysis of variance with Tukey's post hoc adjustment when appropriate. Statistical significance was defined as $\mathrm{P}<0.05$.

\section{Results}

The characteristics of UC-MSCS

The number of adherent cells from tissue fragments increased with time, and the cells became spindle shaped within 7 days. After 10-15 days, a number of classical MSC colonies appeared that were similar to the MSCs isolated from bone marrow (Fig. 1A, 1B). Cells with fat drops can uptake the Oil Red 0 after adipocyte differentiation(Fig. 1D), moreover, after explore with an osteogenic medium, cells with an osteoblast-like phenotype were stained with alizarin red (Fig. 1C). Flow cytometry showed that UC-MSCs were positive for CD44 and CD105, but not for CD34 or CD45, further confirming the MSC characteristic of cells isolated from the UC (Fig. 1E, 1F).

\section{TMZ prevents $H / S D$-induced apoptosis of $M S C S$}

To measure the anti-apoptotic effects of TMZ on MSCs under H/SD conditions, cells that were treated with or without TMZ were analyzed using morphology and flow cytometry. As shown in Figure 2 A, MSCs exposed to H/SD showed increased chromatin condensation compared to the control group by staining with Hoechst 33342. However, cells treated with $10 \mu \mathrm{M}$ TMZ displayed little condensed chromatin. 


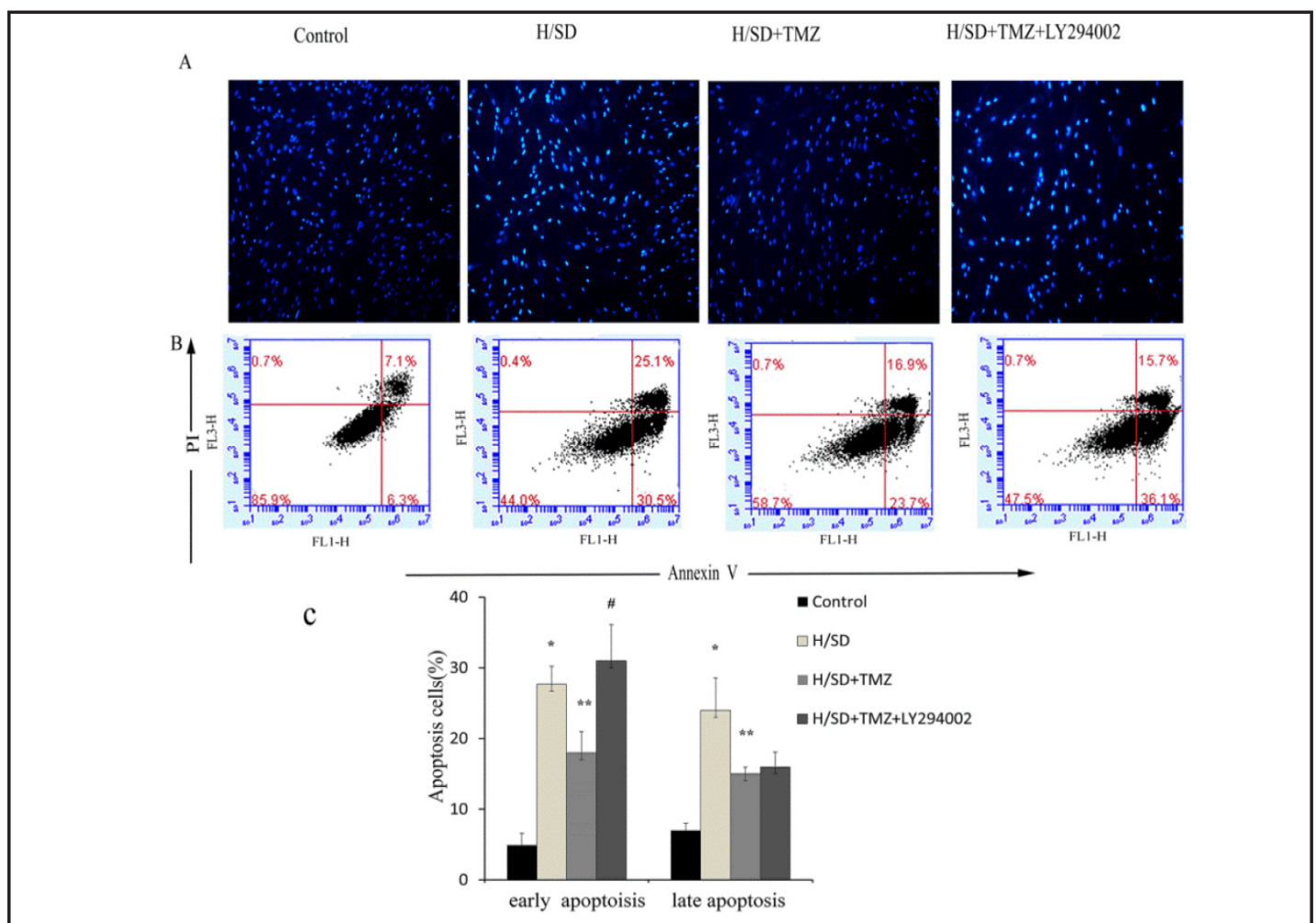

Fig. 2. TMZ protects MSCs against H/SD-induced apoptosis. (A) Nuclear morphology was determined using Hoechst 33342 staining (100X). (B) Apoptosis was quantified by FACS analysis after staining with Annexin $\mathrm{V}$ and propidine iodine (PI). TMZ reduced the level of MSC apoptosis induced by H/SD; however, the antiapoptotic effects of TMZ were significantly abrogated by LY294002, a special Akt inhibitor. (C) Percentage of apoptotic cells in the different groups. The Annexin V + /PI - cells was early apoptosis, whereas the Annexin $\mathrm{V}+/ \mathrm{PI}+$ cells indicated late apoptosis. Each data point represents mean $\pm \mathrm{SD}$ of three independent experiments. ${ }^{*} \mathrm{P}<0.001$ vs Control, ${ }^{* *} \mathrm{P}<0.05$ vs $\mathrm{H} / \mathrm{SD}, \# \mathrm{P}<0.05$ vs $\mathrm{H} / \mathrm{SD}+\mathrm{TMZ}$.

Quantitative analysis using Annexin V/PI staining and flow cytometry revealed that some MSCs were apoptotic and necrotic under the H/SD environment. After exposure to hypoxia for $12 \mathrm{~h}$, the proportion of early stage apoptotic cells decreased significantly from $30.5 \%$ to $23.7 \%$, and the late stage apoptotic cells decreased from $25.1 \%$ to $16.9 \%$ in the $\mathrm{H} /$ $\mathrm{SD}+\mathrm{TMZ}$ group compared to the H/SD group (Fig. 2B, 2C).

\section{TMZ increased MSC viability and proliferation capacity}

As shown in Figure 3, H/SD treatment impaired the viability and proliferation of MSCs; these H/SD-induced impairments were markedly attenuated in the MSC+TMZ group, but LY294002 inhibited this effect. These results suggested that TMZ protected MSCs against injury induced by H/SD.

\section{TMZ decreases caspase-3 activation}

Our results also illustrate the influence of TMZ on H/SD induced caspase- 3 activation. Almost no cleaved caspase- 3 was detected in the control group, but after H/SD treatment, the expression of cleaved caspases-3 markedly increased. Moreover, this effect was attenuated by the H/SD+TMZ group. However, LY24002, a specific Akt inhibitor, reversed the inhibitory effect of TMZ (Fig. 4).

TMZ exerts protective effects on the apoptosis of MSCs via the Akt pathways

We next examined the role of the Akt pathway in the TMZ-mediated anti-apoptotic effects. In an H/SD environment, the expression of p-Akt decreased obviously, however, 


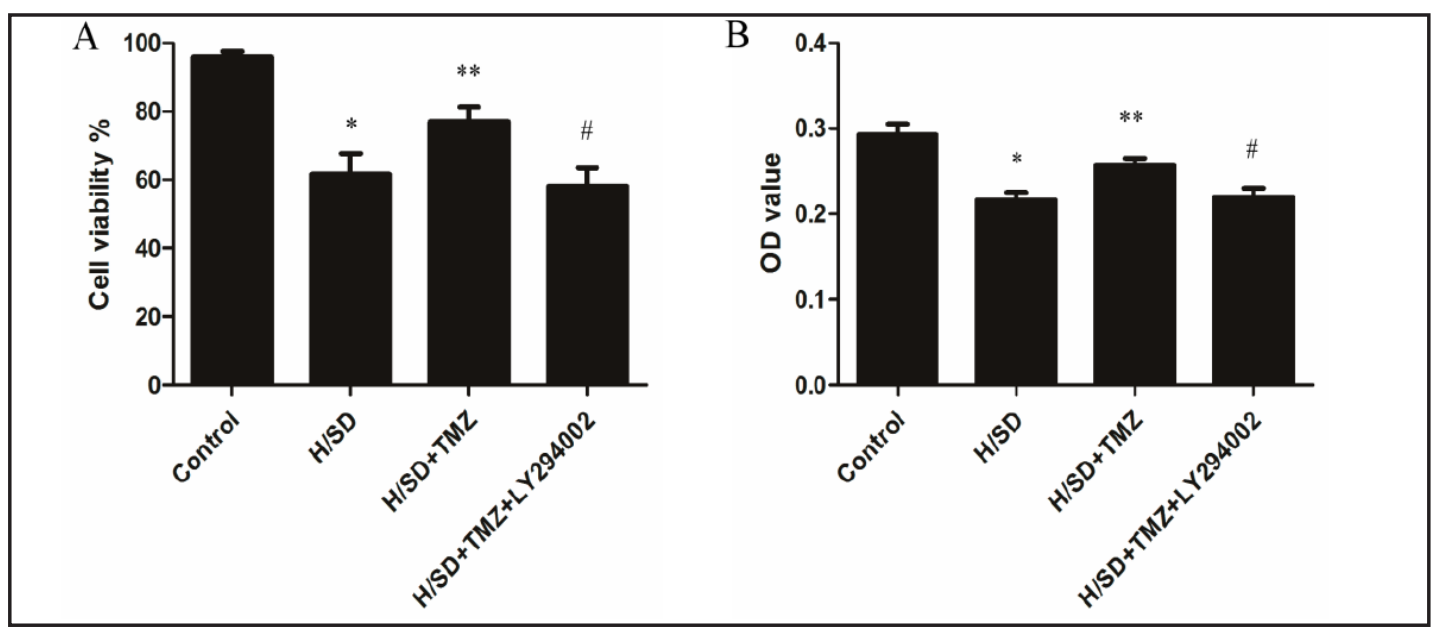

Fig. 3. Effect of TMZ on MSC viability and proliferation. Cell viability (A) and proliferation (B), which were reduced in the H/SD group, increased in H/SD+TMZ group; however, the effect was abrogated by LY294002. ${ }^{*} \mathrm{P}<0.01$ vs Control, ${ }^{* *} \mathrm{P}<0.05$ vs H/SD, \# $\mathrm{P}<0.05$ vs H/SD+TMZ.

Fig. 4. Effects of $\mathrm{TMZ}$ on the activity of caspase-3 in MSCs exposed to H/SD. (A) Cells were exposed to normoxia or hypoxia for $12 \mathrm{~h}$ in either the absence or presence of TMZ. The active subunit of caspase- 3 was detected by Western blot. (B) The histogram shows the relative protein levels normalized to $\beta$-actin. Representative results of three independent experiments are shown. The results are expressed as the means $\pm \mathrm{SD}{ }^{*} \mathrm{p}<0.01$ vs Control, ${ }^{* *} \mathrm{p}<0.05$ vs $\mathrm{H} / \mathrm{SD} ; \# \mathrm{p}<0.05$ vs H/SD+TMZ.

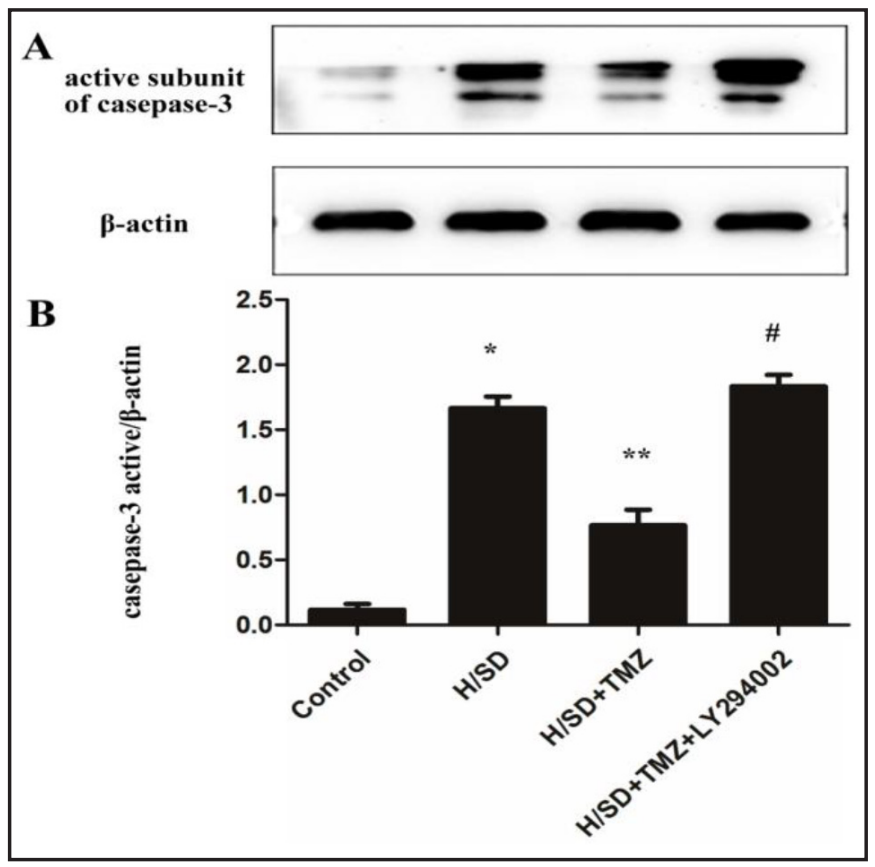

adding TMZ to the culture medium effectively blocked the downregulation of p-Akt at the protein level. In addition, the expression of Bcl-2, an important anti-apoptosis protein, increased upon TMZ administration (Fig. 5).

\section{LY294002 blocked the protective effect of TMZ to H/SD induced apoptosis}

To understand whether the beneficial effect of TMZ on MSCs is Akt dependent, MSCs were pretreated with an Akt inhibitor, LY294002 (25 $\mu \mathrm{M})$. Consistent with our initial studies, 12 hours of hypoxia exposure significantly decreased Akt phosphorylation in MSCs; this decrease in Akt phosphorylation was prevented by TMZ treatment. In contrast, incubation of MSCs with both TMZ and LY294002 prevented the phosphorylation of Akt ( $<<0.01)$, as shown in Figure 5.

Meantime, treatment with LY294002 markedly increased the apoptosis of MSCs under $\mathrm{H} / \mathrm{SD}$, as determined by increased chromatin condensation and early stage apoptotic cell 


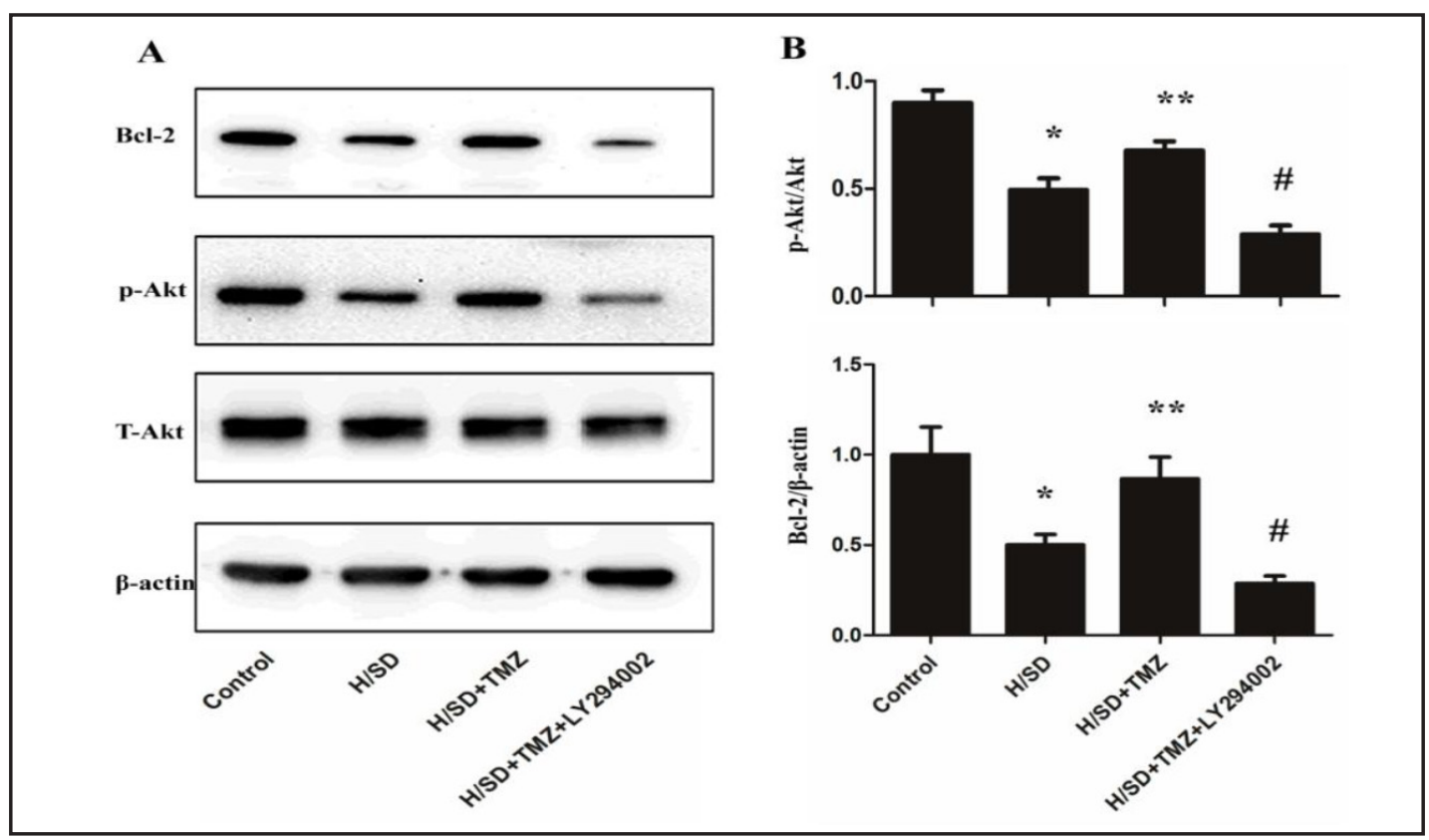

Fig. 5. TMZ activated the Akt pathway in MSCs. (A) The expression levels of total Akt, phosphorylated Akt and Bcl-2 were measured by Western blot. The phosphorylation of Akt and Bcl-2 significantly increased after treatment with $10 \mu \mathrm{M}$ TMZ. (B) Histograms show the results of the relative protein level normalized to $\beta$-actin. The results are expressed as the means \pm SD from three independent experiments. ${ }^{*} \mathrm{p}<0.01 \mathrm{vs}$ Control, ${ }^{* *} \mathrm{p}<0.05$ vs H/SD, \# $\mathrm{p}<0.01$ vs H/SD+TMZ.

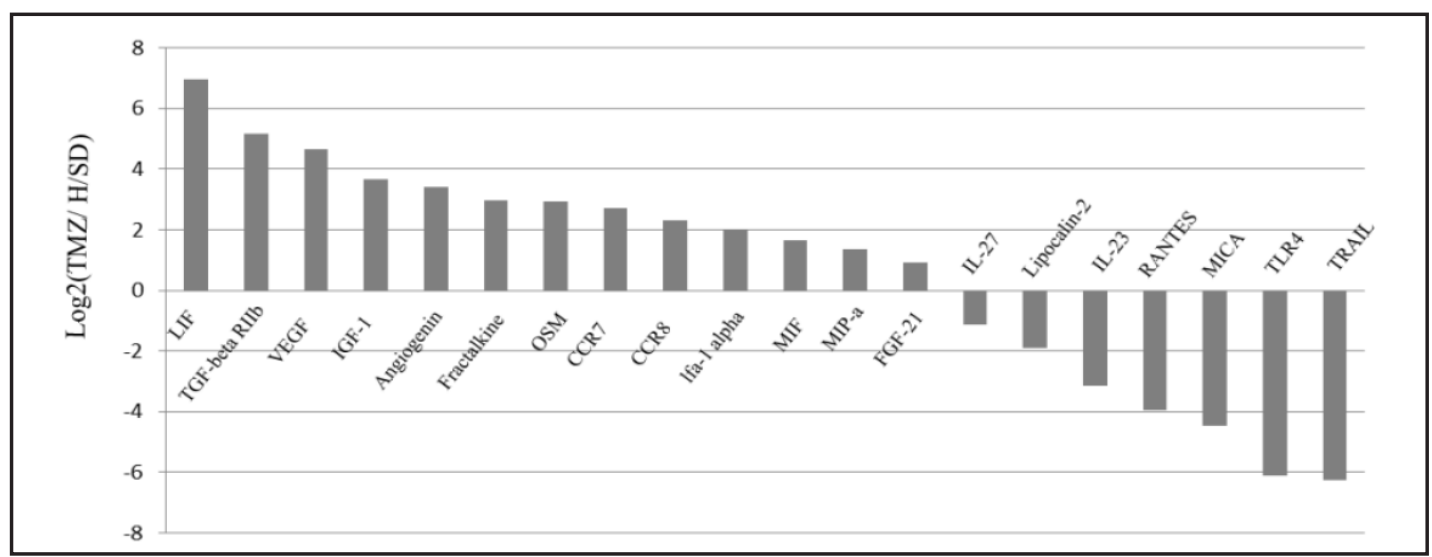

Fig. 6. TMZ treatment promoted the paracrine functions of UC-MSCs. Protein chip assay showed that 20 molecules were differentially expressed between the TMZ group and H/SD group. These values are expressed on a log scale. In TMZ group, MSCs secrete more anti-inflammatory cytokine, regeneration and chemotactic factors.

(Fig. 2). The expression levels of apoptosis proteins also changed: p-Akt and Bcl-2 (Fig. 5) decreased, and casepase-3 increased (Fig. 3).

$T M Z$ promoted the paracrine functions of UC-MSCS

We further studied whether TMZ improved the paracrine functions of H/SD induced MSCs. Various cell cytokines, chemokines, growth, inflammation, apoptosis factor and receptors were detected in cultures from $\mathrm{H} / \mathrm{SD}$ and $\mathrm{H} / \mathrm{SD}+\mathrm{TMZ}$ groups. Thirteen molecules were detected at higher levels in the TMZ group than in the H/SD group: LIF, TGF-beta RIIb, VEGF, IGF-1, Angiogenin, Fractalkine, OSM, CCR7, CCR8, LFA-1 alpha, MIF, MIP-1a and FGF- 
21. Seven molecules were detected at higher densities in the H/SD group than in the TMZ group: TRAIL, TLR4, MICA, RANTES, IL-23, Lipocalin-2 and IL-27 (Fig. 6).

\section{Discussion}

In the present study, our results demonstrate that TMZ improves the viability and attenuates the apoptosis of MSCs subjected to 12 hours of H/SD conditions. The effect was mediated through the activation of the Akt pathway, revealing the Akt pathway as a potential target to improve MSC survival in cell transplantation therapy.

Numerous studies have demonstrated that MSC therapy has great promise for regenerating damaged myocardium $[15,16]$. However, the efficacy of the therapy is limited by the poor viability of MSCs transplanted into the infracted heart $[17,18]$. For example, Mazo et al. could not detect any injected adipose derived MSCs in hearts 30 days after transplantation [19]; and Tang et al. showed the survival of engrafted MSC in ischemic myocardium was significantly lower on 24 hours $(7.6 \pm 1.3 \%)$ and 7 days $(3.6 \pm 1.9 \%)$ after transplantation[20], These studies imply that the ischemic microenvironment is not suitable for MSC survival. Hence, improving the survival of transplanted MSCs in the harmful myocardial environment is necessary. Many drugs that exert protective effects against $\mathrm{H}$ / SD induced apoptosis in MSCs have been well documented, including Atorvastatin [21], Lovastatin [22] and Tongxinluo [23].

TMZ, an antianginal drug, protects ischemic cardiomyocytes by restoring their ability to produce energy, and has been widely used to treat various cardiovascular diseases such as coronary heart disease and heart failure [24, 25]. In basic medical science, TMZ has been demonstrated to have pleiotropic effects. For example, it inhibits cardiomyocyte apoptosis [26], protects endothelial progenitor cells against $\mathrm{H}_{2} \mathrm{O}_{2}$-induced injury [9], reduces mitochondria-dependent oxidative stress and increases mitochondrial generation of NO [27]. However, it is not known whether TMZ can inhibit the H/SD induced apoptosis of MSCs, particularly MSCs of human origin.

Moreover, Many studies have confirmed that hypoxia is protective for stem cells, and can promote proliferation [28], differentiation [29], paracrine activity [30], recruitment and homing [31]. However, the protective effects depend on the oxygen tension, time in culture, serum deprivation conditions, the source of the MSCs, and other culture conditions, especially the serum deprivation, Zhu et al. [32]. and Potier et al [33]. showed that rat MSCs were able to withstand hypoxia only when they were not also deprived of serum, but the underlying protective mechanisms are complicated [34]. We believe that a standardized protocol for hypoxic culture could lead to a better consensuses of the effects of hypoxia on MSCs.

In the present study, we focused on the favorable effects of TMZ on human umbilical cord MSCs in an H/SD environment and demonstrate the important role of the Akt pathway in the protective effects. As is known to all, the Akt pathway participates in a variety of cell biological functions, including apoptosis, proliferation and survival $[35,36]$. Moreover, Mangi et al. reported that MSCs that were genetically enhanced with Akt can repair infarcted myocardium, prevent remodeling and nearly normalize cardiac performance [37]. Therefore, we investigated the role of Akt pathway in the TMZ-mediated anti-apoptotic effects on MSCs.

In our study, H/SD decreased the expression of p-Akt, implying that many favorable physiological activities mediated by the Akt pathway are impaired by H/SD. However, TMZ treatment reversed the suppression of p-Akt caused by H/SD. To further investigate this hypothesis, we pretreated MSCs with the specific Akt inhibitor LY294002 and found that the expression of p-Akt decreased and TMZ-mediated anti-apoptotic effects were significantly attenuated, further supporting the importance of the Akt pathway in protecting MSCs. These results were consistent with many earlier studies that showed that the expression of Akt helps to prevent apoptosis in different settings. For example, Zhang et al. suggested that the activation of the Akt pathway limits JNK-mediated apoptosis during EV71 infection [38], Fujio et al. found that Akt promotes the survival of cardiomyocytes in vitro and protects against ischemia-reperfusion injury in mouse heart [39]. 
In addition, a previous study performed in rats with a myocardial infarction revealed that pharmacologically preconditioning MSCs with TMZ protects hypoxic cells against oxidative stress and enhances the recovery of myocardial function via Bcl-2 expression [14]. Our results also showed a marked increase in the expression of Bcl-2 in the MSC+TMZ group. Moreover, the increased expression of Bcl-2 was inhibited by LY294002, similar to the expression of p-Akt.

We further examined the regulatory effects of H/SD on the activation of the caspase- 3 protein, which is a key mediator of apoptosis induced by the mitochondrial pathway. Zhu et al. suggested that MSCs undergo caspase-dependent apoptosis in response to H/SD [32]. Consistent with this report, we also found that the level of caspase- 3 increased in the cells treated with H/SD compared to the control cells. However, this caspase-3 activation increase was prevented by TMZ administration. Finally, the reduction of MSC apoptosis by TMZ treatment correlated with an increase in Bcl-2 and a decrease in caspase- 3 activation in this study.

Finally, we employed a protein chip assay to detect the effects of TMZ on the paracrine functions of MSCs, and found that TMZ promoted the paracrine functions of MSCs, which secreted more anti-inflammatory cytokine; and regeneration and chemotactic factors into the media, including LIF, VEGF, IGF-1 and Angiogenin. Moreover, more apoptosis and inflammatory factors were found in the H/SD group, including IL-23, IL-7 and TLR4. These findings are consistent with those of Liu and Hwang, who reported that cord blood MSCs secreted chemokines, growth factors, angiogenic factors and cytokines into supernatant [40]. Importantly, paracrine factors in conditioned media are responsible for the pro-survival response and exert anti-apoptotic and anti-inflammatory effects [41]. Many studies have confirmed that hypoxia increases the secretion of biological factors in MSCs [42, 43]. In the present study; we found that TMZ also had this effect, suggesting that TMZ could potentially be used as a new pretreatment method to promote the paracrine functions of stem cells in transplantation.

There are some limitations to our study. First, only one concentration of TMZ was studied, and so it is unknown whether the protective effects of TMZ are dose-dependent, and further studies are needed. Second, the mitogen-activated protein kinase/extracellular signal regulated kinase (MEK/ERK) pathway is also important in mediating cell survival [44], but we did not examine its role in MSC apoptosis. More importantly, it is necessary to use an animal model of myocardial infarction to assess the efficacy of cell therapy using TMZmanipulated MSCs.

In conclusion, the present study demonstrates that TMZ ameliorated H/SD-induced apoptosis in MSCs via the Akt signaling pathway. Thus, administering TMZ along with MSCs transplantation may be a novel strategy to improve MSC survival in infarcted myocardium.

\section{Acknowledgments}

The work was supported by grants from the Specialized Research Fund for the Doctoral Program of Higher Education (2012110611045).

\section{Disclosure Statement}

None.

\section{References}

1 Moran AE, Forouzanfar MH, Roth GA, Mensah GA, Ezzati M, Flaxman A, Murray CJ, Naghavi M: The global burden of ischemic heart disease in 1990 and 2010: The global burden of disease 2010 study. Circulation 2014;129:1493-1501.

-2 Schmidt MR, Pryds K, Botker HE: Novel adjunctive treatments of myocardial infarction. World J Cardiol 2014;6:434-443. 


\section{Cellular Physiology Cell Physiol Biochem 2014;34:2245-2255 and BiOchemistry \begin{tabular}{l|l}
$\begin{array}{l}\text { DOI: 10.1159/000369667 } \\
\text { Published online: December 08, } 2014\end{array}$ & $\begin{array}{l}\text { C 2014 S. Karger AG, Basel } \\
\text { www.karger.com/cpb }\end{array}$ \\
\hline Gong et al.: Trimetazidine Reduces Apoptosis of Mesenchymal Stem Cells by Activation
\end{tabular} of Akt}

3 Przybyt E, Harmsen MC: Mesenchymal stem cells: Promising for myocardial regeneration? Curr Stem Cell Res Ther 2013;8:270-277.

4 Vassalli G, Moccetti T: Cardiac repair with allogeneic mesenchymal stem cells after myocardial infarction. Swiss Med Wkly 2011;141:w13209.

5 Wollert KC, Meyer GP, Lotz J, Ringes-Lichtenberg S, Lippolt P, Breidenbach C, Fichtner S, Korte T, Hornig B, Messinger D, Arseniev L, Hertenstein B, Ganser A, Drexler H: Intracoronary autologous bone-marrow cell transfer after myocardial infarction: The boost randomised controlled clinical trial. Lancet 2004;364:141148.

6 Lunde K, Solheim S, Aakhus S, Arnesen H, Abdelnoor M, Egeland T, Endresen K, Ilebekk A, Mangschau A, Fjeld JG, Smith HJ, Taraldsrud E, Grogaard HK, Bjornerheim R, Brekke M, Muller C, Hopp E, Ragnarsson A, Brinchmann JE, Forfang K: Intracoronary injection of mononuclear bone marrow cells in acute myocardial infarction. N Engl J Med 2006;355:1199-1209.

7 Zhang M, Methot D, Poppa V, Fujio Y, Walsh K, Murry CE: Cardiomyocyte grafting for cardiac repair: Graft cell death and anti-death strategies. J Mol Cell Cardiol 2001;33:907-921.

8 Stadnik M, Handzlik-Orlik G, Sarnecki K, Krysiak R, Okopien B: [clinical aspects of the use of trimetazidine in the prevention and treatment of myocardial diseases]. Przegl Lek 2013;70:730-734.

-9 Wu Q, Qi B, Liu Y, Cheng B, Liu L, Li Y, Wang Q: Mechanisms underlying protective effects of trimetazidine on endothelial progenitor cells biological functions against h2o2-induced injury: Involvement of antioxidation and akt/enos signaling pathways. Eur J Pharmacol 2013;707:87-94.

10 Xu H, Zhu G, Tian Y: Protective effects of trimetazidine on bone marrow mesenchymal stem cells viability in an ex vivo model of hypoxia and in vivo model of locally myocardial ischemia. J Huazhong Univ Sci Technolog Med Sci 2012;32:36-41.

11 Fu YS, Cheng YC, Lin MY, Cheng H, Chu PM, Chou SC, Shih YH, Ko MH, Sung MS: Conversion of human umbilical cord mesenchymal stem cells in wharton's jelly to dopaminergic neurons in vitro: Potential therapeutic application for parkinsonism. Stem Cells 2006;24:115-124.

12 Hsieh JY, Wang HW, Chang SJ, Liao KH, Lee IH, Lin WS, Wu CH, Lin WY, Cheng SM: Mesenchymal stem cells from human umbilical cord express preferentially secreted factors related to neuroprotection, neurogenesis, and angiogenesis. PloS One 2013;8:e72604.

13 Dominici M, Le Blanc K, Mueller I, Slaper-Cortenbach I, Marini F, Krause D, Deans R, Keating A, Prockop D, Horwitz E: Minimal criteria for defining multipotent mesenchymal stromal cells. The international society for cellular therapy position statement. Cytotherapy 2006;8:315-317.

14 Wisel S, Khan M, Kuppusamy ML, Mohan IK, Chacko SM, Rivera BK, Sun BC, Hideg K, Kuppusamy P: Pharmacological preconditioning of mesenchymal stem cells with trimetazidine (1-[2,3,4-trimethoxybenzyl]piperazine) protects hypoxic cells against oxidative stress and enhances recovery of myocardial function in infarcted heart through bcl-2 expression. J pharmacol Exp Ther 2009;329:543-550.

15 Nascimento DS, Mosqueira D, Sousa LM, Teixeira M, Filipe M, Resende TP, Araujo AF, Valente M, Almeida J, Martins JP, Santos JM, Barcia RN, Cruz P, Cruz H, Pinto-do OP: Human umbilical cord tissue-derived mesenchymal stromal cells attenuate remodeling following myocardial infarction by pro-angiogenic, antiapoptotic and endogenous cell activation mechanisms. Stem cell Res Ther 2014;5:5.

16 Miyahara Y, Nagaya N, Kataoka M, Yanagawa B, Tanaka K, Hao H, Ishino K, Ishida H, Shimizu T, Kangawa K, Sano S, Okano T, Kitamura S, Mori H: Monolayered mesenchymal stem cells repair scarred myocardium after myocardial infarction. Nat Med 2006;12:459-465.

17 van der Bogt KE, Sheikh AY, Schrepfer S, Hoyt G, Cao F, Ransohoff KJ, Swijnenburg RJ, Pearl J, Lee A, Fischbein M, Contag CH, Robbins RC, Wu JC: Comparison of different adult stem cell types for treatment of myocardial ischemia. Circulation 2008;118:S121-129.

18 Imanishi Y, Saito A, Komoda H, Kitagawa-Sakakida S, Miyagawa S, Kondoh H, Ichikawa H, Sawa Y: Allogenic mesenchymal stem cell transplantation has a therapeutic effect in acute myocardial infarction in rats. J Mol Cell Cardiol 2008;44:662-671.

19 Mazo M, Planat-Benard V, Abizanda G, Pelacho B, Leobon B, Gavira JJ, Penuelas I, Cemborain A, Penicaud L, Laharrague P, Joffre C, Boisson M, Ecay M, Collantes M, Barba J, Casteilla L, Prosper F: Transplantation of adipose derived stromal cells is associated with functional improvement in a rat model of chronic myocardial infarction. Eur J Heart Fail 2008;10:454-462.

-20 Tang YL, Tang Y, Zhang YC, Qian K, Shen L, Phillips MI: Improved graft mesenchymal stem cell survival in ischemic heart with a hypoxia-regulated heme oxygenase-1 vector. J Am Coll of Cardiol 2005;46:13391350 . 


\section{Cellular Physiology $\quad$ Cell Physiol Biochem 2014;34:2245-2255

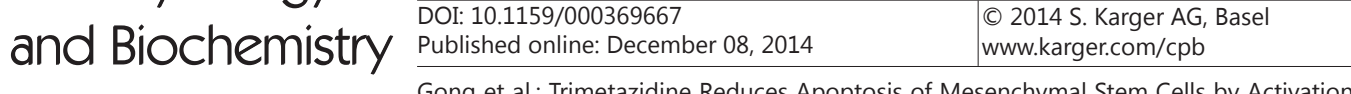 of Akt}

21 Song L, Yang YJ, Dong QT, Qian HY, Gao RL, Qiao SB, Shen R, He ZX, Lu MJ, Zhao SH, Geng YJ, Gersh BJ: Atorvastatin enhance efficacy of mesenchymal stem cells treatment for swine myocardial infarction via activation of nitric oxide synthase. PloS One 2013;8:e65702.

22 Xu R, Chen J, Cong X, Hu S, Chen X: Lovastatin protects mesenchymal stem cells against hypoxia- and serum deprivation-induced apoptosis by activation of pi3k/akt and erk1/2. J Cell Biochem 2008;103:256-269.

-23 Li N, Yang YJ, Cui HH, Zhang Q, Jin C, Qian HY, Dong QT, Zhang H: Tongxinluo decreases apoptosis of mesenchymal stem cells concentration-dependently under hypoxia and serum deprivation conditions through the ampk/enos pathway. J Cardiovasc Pharmacol 2014;63:265-273.

24 Kim JS, Kim CH, Chun KJ, Kim JH, Park YH, Kim J, Choi JH, Lee SH, Kim EJ, Yu DG, Ahn EY, Jeong MH: Effects of trimetazidine in patients with acute myocardial infarction: Data from the korean acute myocardial infarction registry. Clin Res Cardiol 2013;102:915-922.

-25 Tsioufis K, Andrikopoulos G, Manolis A: Trimetazidine and cardioprotection: Facts and perspectives. Angiology DOI: 10.1177/0003319714530040.

-26 Ruixing Y, Wenwu L, Al-Ghazali R: Trimetazidine inhibits cardiomyocyte apoptosis in a rabbit model of ischemia-reperfusion. Transl Res 2007;149:152-160.

-27 Dedkova EN, Seidlmayer LK, Blatter LA: Mitochondria-mediated cardioprotection by trimetazidine in rabbit heart failure. J Mol Cell Cardiol 2013;59:41-54.

-28 Grayson WL, Zhao F, Bunnell B, Ma T: Hypoxia enhances proliferation and tissue formation of human mesenchymal stem cells. Biochem Biophys Res Commun 2007;358:948-953.

29 Potier E, Ferreira E, Andriamanalijaona R, Pujol JP, Oudina K, Logeart-Avramoglou D, Petite H: Hypoxia affects mesenchymal stromal cell osteogenic differentiation and angiogenic factor expression. Bone 2007;40:1078-1087.

-30 Ohnishi S, Yasuda T, Kitamura S, Nagaya N: Effect of hypoxia on gene expression of bone marrow-derived mesenchymal stem cells and mononuclear cells. Stem Cells 2007;25:1166-1177.

-31 Rochefort GY, Delorme B, Lopez A, Herault O, Bonnet P, Charbord P, Eder V, Domenech J: Multipotential mesenchymal stem cells are mobilized into peripheral blood by hypoxia. Stem Cells 2006;24:2202-2208.

-32 Zhu W, Chen J, Cong X, Hu S, Chen X: Hypoxia and serum deprivation-induced apoptosis in mesenchymal stem cells. Stem Cells 2006;24:416-425.

-33 Potier E, Ferreira E, Meunier A, Sedel L, Logeart-Avramoglou D, Petite H: Prolonged hypoxia concomitant with serum deprivation induces massive human mesenchymal stem cell death. Tissue Eng 2007;13:13251331.

-34 Das R, Jahr H, van Osch GJ, Farrell E: The role of hypoxia in bone marrow-derived mesenchymal stem cells: Considerations for regenerative medicine approaches. Tissue Eng Part B Rev 2010;16:159-168.

-35 Herrmann JL, Markel TA, Abarbanell AM, Weil BR, Wang M, Wang Y, Tan J, Meldrum DR: Proinflammatory stem cell signaling in cardiac ischemia. Antioxid Redox Signal 2009;11:1883-1896.

-36 Sussman MA, Volkers M, Fischer K, Bailey B, Cottage CT, Din S, Gude N, Avitabile D, Alvarez R, Sundararaman B, Quijada P, Mason M, Konstandin MH, Malhowski A, Cheng Z, Khan M, McGregor M: Myocardial akt: The omnipresent nexus. Physiol Rev 2011;91:1023-1070.

-37 Mangi AA, Noiseux N, Kong D, He H, Rezvani M, Ingwall JS, Dzau VJ: Mesenchymal stem cells modified with akt prevent remodeling and restore performance of infarcted hearts. Nat Med 2003;9:1195-1201.

-38 Zhang H, Li F, Pan Z, Wu Z, Wang Y, Cui Y: Activation of pi3k/akt pathway limits jnk-mediated apoptosis during ev71 infection. Virus Res 2014;192:74-84.

-39 Fujio Y, Nguyen T, Wencker D, Kitsis RN, Walsh K: Akt promotes survival of cardiomyocytes in vitro and protects against ischemia-reperfusion injury in mouse heart. Circulation 2000;101:660-667.

40 Liu CH, Hwang SM: Cytokine interactions in mesenchymal stem cells from cord blood. Cytokine 2005;32:270-279.

41 Boomsma RA, Geenen DL: Mesenchymal stem cells secrete multiple cytokines that promote angiogenesis and have contrasting effects on chemotaxis and apoptosis. PloS One 2012;7:e35685.

42 Jin H, Sanberg PR, Henning RJ: Human umbilical cord blood mononuclear cell-conditioned media inhibits hypoxic-induced apoptosis in human coronary artery endothelial cells and cardiac myocytes by activation of the survival protein akt. Cell Transplant 2013;22:1637-1650.

43 Du L, Yu Y, Ma H, Lu X, Ma L, Jin Y, Zhang H: Hypoxia enhances protective effect of placental-derived mesenchymal stem cells on damaged intestinal epithelial cells by promoting secretion of insulin-like growth factor-1. Int J Mol Sci 2014;15:1983-2002.

44 Risbud MV, Fertala J, Vresilovic EJ, Albert TJ, Shapiro IM: Nucleus pulposus cells upregulate pi3k/akt and mek/erk signaling pathways under hypoxic conditions and resist apoptosis induced by serum withdrawal. Spine 2005;30:882-889. 